\title{
Eco Labels and Eco Conscious Consumer Behavior: The Mediating Effect of Green Trust and Environmental Concern
}

\author{
Irfan Hameed * $\quad$ Idrees Waris ${ }^{\dagger}$
}

\begin{abstract}
This study explores the relationship between eco labels and eco conscious consumer behavior for green products. Mediation effect of consumer trust regarding green products and their concern for the sustainability of environment have also been analyzed. There are many researches regarding consumers' evaluation of green products and consumer behavior, but no substantial research has been done on the effects of understanding eco labels on eco-conscious consumer behavior. Eco labels are the essential sources of information regarding products' features and focus on providing information about less detrimental effects of green products on environment. Data of respondents have been collected through convenience sampling from the most populous city of Pakistan, i.e., Karachi. This research is an empirical study, structural equation modelling technique has been used to explore the relationship among the variables in the study. Furthermore, the mediation effects of green trust and environmental concern on consumer' behavior have also been analyzed. The findings of research highlight the positive impact of eco labels on consumers' eco conscious behavior. The results show full mediation effect of green trust on the relationship between eco labels and eco conscious consumer behavior. However, there was no mediation effect of environmental concern between eco labels and eco conscious consumer behavior. Hence, investing resources on eco labels design and providing awareness about the sustainability of environment are helpful in producing eco conscious consumer behavior.
\end{abstract}

Keywords: Eco labels, eco conscious consumer behavior, green trust, environmental concern.

\section{Introduction}

Environmental issues have become a concern for the consumers and companies across the globe that led to the manufacturing of green products (Bailey, Mishra, \& Tiamiyu, 2016). Green marketing encompasses broad range of concepts which includes facilitation and production of value satisfying consumer's needs and demands (Martínez, 2015). Hence, it is essential for the marketers to portray green products as healthy as well as environmental friendly (Rettie, Burchell, \& Riley, 2012).

Green marketing signifies social responsibility of a firm. Green marketing is an effort to maintain and build sustainable relationship with stakeholders e.g., nature, society and consumers. Thus, it includes marketing of green products and services is a sustainable process and shapes the attitude of the society towards pro environmental behavior (Rettie et al., 2012). Power of marketing is undeniable in acting as a change agent and amending government policies in the support of green orientation (Gordon, Carrigan,

\footnotetext{
* Registrar \& Chairperson, Department of Marketing, IQRA University, Karachi, Pakistan.

E-mail: irfan.h@iqra.edu.pk

${ }^{\dagger}$ Lecturer, Management Sciences, University of Turbat, Turbat, Pakistan. E-mail: idrees.waris@uot.edu.pk
} 
\& Hastings, 2011). Marketing has a vital role in driving sales of companies, improving performance and increasing market share. However, the results of green marketing strategies from previous study suggest diminishing sales and performance in terms of market shares (D'Souza, Taghian, Sullivan-Mort, \& Gilmore, 2015). Classical researchers were more interested in motivating consumers to become more environmentally friendly. Marketers have emphasized on the benefits of recycled products and consumer decision making processes to involve them in green consumption. Apart from motivating, they had the instinct to get value and leverage by the generation of new segments of consumer markets (Polonsky, 2011).

Eco labels is the emerging trend in green marketing that is effective source for consumer information (Testa, Iraldo, Vaccari, \& Ferrari, 2015). Particularly, it provides relevant green product information to the consumers during purchase decisions (Thøgersen, Haugaard, \& Olesen, 2010). Plethora of marketing literature exists depicting eco labels effectiveness in the promotion of green products (Hornibrook, May, \& Fearne, 2015).

Numerous researches in the field of marketing have focused on the Theory of Reasoned Action (TRA) (Fishbein \& Ajzen, 1980). Theory of Reasoned Action proposed that individual's behavior is associated with the attitude which is formed by the positive and negative evaluation of beliefs (Fishbein \& Ajzen, 1977). TRA suggests that attaining a behavior is based upon individual preexisting behavioral intentions. In the core of this theory, behavior is the product of intention which itself, is the result of subjective norms and attitude towards a specific stimulus. However, some researchers have identified weak link between individual intention and behavior (Davies, Foxall, \& Pallister, 2002). Agreeing on this evidence, Polonsky, Vocino, Grau, Garma, and Ferdous (2012) proposed self-reported actual behavior model. This article is based on the TRA framework model, which was valid in determining the link between consumer's environment friendly attitude and behavior (Gotschi, Vogel, Lindenthal, \& Larcher, 2009). This paper uses eco labels as the predictor of consumer attitude for environmental concern and attitude towards green trust which ultimately lead to eco conscious consumer behavior.

A visible gap can be found in the literature regarding the effectiveness of eco labels and eco-conscious consumer behavior, while most of the researchers have focused on eco labels and purchase of green products or consumer awareness and inclination for the green products. This paper aims to fill the gap around green marketing by focusing eco labels effectiveness in forming eco-conscious consumer behavior. Eco-labels are an integrated part of green marketing that project company's green image to consumers. It also provides information to consumers related to products' features and sustainability of environment. In a developing country like Pakistan, importance of green labels is paramount as it will eventually affect decision making of an environmentally friendly consumer. Thus, it is essential to study the effectiveness of eco-labels eliciting consumer response for the consumption of green products. 


\section{Literature Review}

\section{The Emergence of the Green Consumer Segment}

There has been increasing concern for the sustainability of the environment amongst consumers since 1960s. Consumers have deep concern for the protection and sustainability of environment. As a result, they are continuously involved in information seeking related to use of scarce resources and recycling of the products. Organizations have also realized the need to target environmental friendly consumers (Zinkhan \& Carlson, 1995). Marketers are trying to promote company's products to generate sales and satisfy individual needs in connection with green strategies (Leonidou, Katsikeas, \& Morgan, 2013). However, they failed to translate pro-environmental concern of consumers to drive sales. Some factors affecting consumers' negative perception about green products are: ineffective marketing strategies, higher prices of green products, companies own performance to deliver the quality products, and above all, consumers trust deficit for green products (Sheth, Sethia, \& Srinivas, 2011). In this nexus, there are many other factors that could be associated with the adoption of green products such as environmental concern, perceived environmental responsibility, perceived environmental seriousness and green purchase behavior of consumers (Chan, 2014). Therefore, it has become essential for a marketer to understand demand and viability of the green segment in long term perspective. This strategy involves different dimensions of marketing ranging from creating demand, understanding consumer psychology regarding green products, consumers' acceptability of green products and demographic variables that affect consumer's decision making regarding the selection of environmentally friendly products (D'Souza et al., 2015). In fact, in B2B, environmental values have high regard as environmentally concerned companies have gained plenty of advantages through enhanced customer response (Mustonen, Karjaluoto, \& Jayawardhena, 2016).

\section{Green Consumer Behavior}

According to Polonsky (2011), consumers have a self-developed decision-making process which resist them from acting environmentally friendly, thus they compromise future of environment by their consumption patterns. Delmas and Lessem (2017) noted that message and attributes of the green products have vital importance in the selection of product. Marketers communicate products attribute through eco labels, if a consumer is well informed and have deep knowledge about green attributes, assesses the quality, they would eventually select a product. Wei, Chiang, Kou, and Lee (2017) investigated that consumers who have high belief regarding the environment, are more inclined towards the products that have minimal adverse impact on the sustainability of the environment.

According to Cronin, Smith, Gleim, Ramirez, and Martinez (2011), green consumers are assessed by their involvement in green activities, those who prefer to use environmental friendly products have been labelled as green consumers and vice versa. Green and Peloza (2014) noted that there has been a shift in marketing strategy in nexus to environment. Companies have formulated strategies to attract future demand of consumers by 


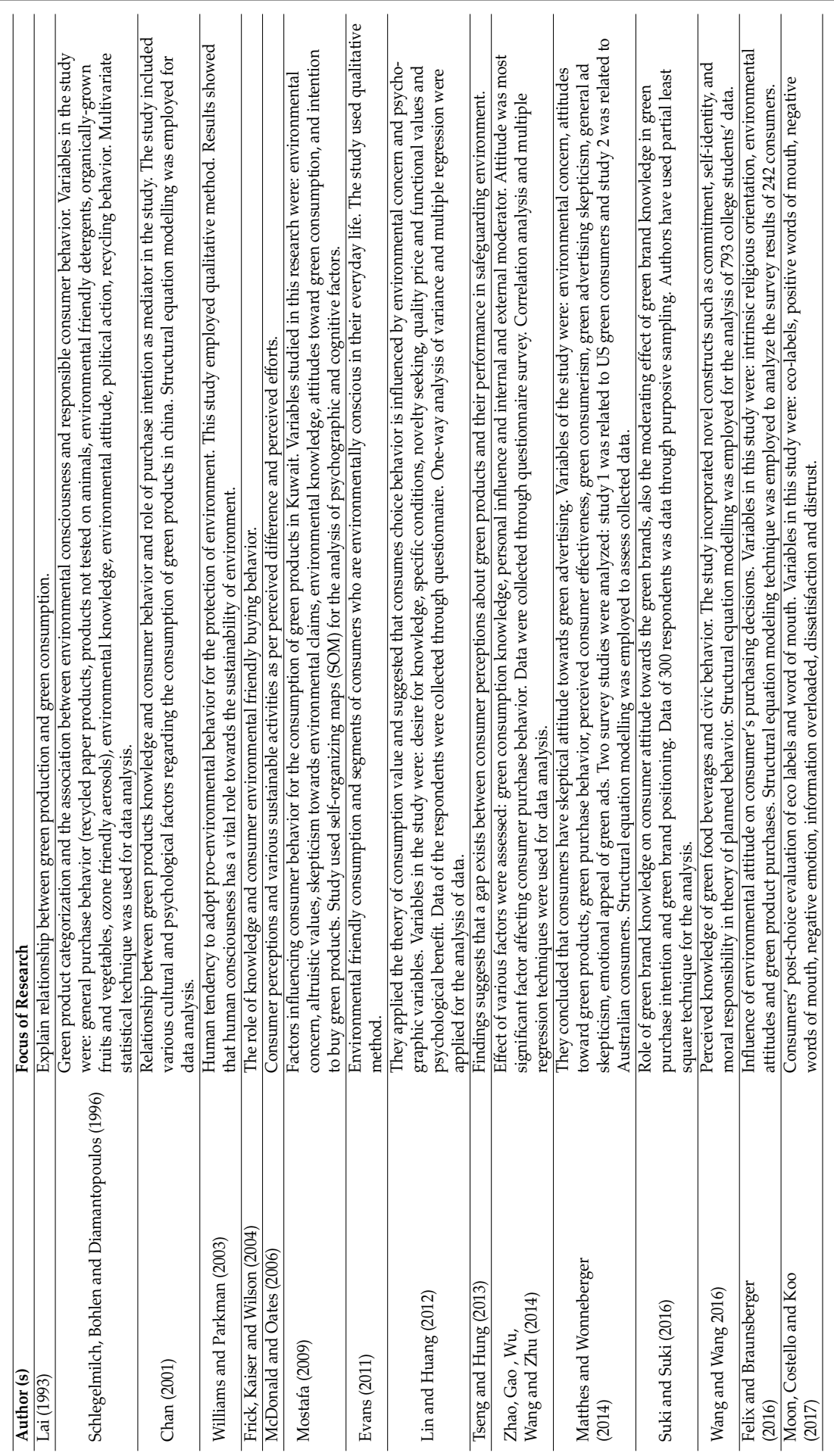


providing information regarding sustainability of the planet. Martínez (2015) argues that companies have formulated marketing strategies to determine belief and attitude of the consumers toward their products. Consequently, it helps to form green image reputation for the organization which ultimately benefit in shape of consumers acceptability of green products and post purchase satisfaction. Eco labels provide information to consumers related to green products, but consumers reject products after assessing different aspects of the eco labels (Thøgersen et al., 2010). It also provides information related to sustainability of the planet and fill the gaps which are hidden in general product labelling (Delmas \& Lessem, 2017). It can be easily assumed that consumers who understand the information on eco labels will form positive image for the green products, which result in information utility over time. According to above justification, it can be hypothesized that:

\section{$H_{1}$ : Consumers' understanding of eco labels will positively influence Eco conscious consumer behavior.}

\section{Eco Labels and Green Trust}

Green trust of the consumer in connection to environment denotes the credible, reliable and standard performance of the firm. Authors have examined that green trust includes reliable, dependable, meeting consumers' expectations, trustworthy and products ability to ensure the safety of environment (Chen \& Chang, 2013). Eco labels is the transparent mean of providing information to consumers about the products that are less damaging to the environment. Eco labels increase consumers ability to judge products potential effects on environment at the point of purchase (Thøgersen et al., 2010). Eco labels is the most reliable source of information for the consumers to evaluate products. Consumers trust increases when companies use certified eco labels to promote their green products. Use of third party certification is an effective way of attracting consumers towards the products and form their environmental behavior. Through eco labels using companies could send clear and effective signal to consumers regarding their performance to ensure sustainability of the environment (Testa et al., 2015). Non-governmental organizations and government agencies have the authority to certify companies' products as green and environmental friendly. Role of these agencies is to maximize trust factor between consumers and producers, and accelerate consumption of green products to protect the environment (Delmas \& Lessem, 2017). Consumers have formed skeptical attitude towards the claims made by companies regarding environmental friendly products. Lee, Bhatt, and Suri (2018) postulated that companies need to promote green products by applying all green attributes, as consumers could easily differentiate between green attributes and greenwashed products. Effective advertising can help a firm in generating favorable attitude towards the brand (Hameed, Siddiqui, \& Husain, 2016). Evidences from various researches suggest that consumers are very conscious about greenwashing and don't rely on advertising regarding green performance of organizations. So, it is hypothesized that:

$\mathrm{H}_{2}$ : Consumers' understanding of eco labels positively influence trust on green claims for green products. 


\section{Trust on Eco Labels affects Consumer Eco Conscious Buying Behavior}

According to Testa et al. (2015), consumers have established a positive attitude for the consumption of environmental friendly products because they have developed associations with the brands. Atkinson and Rosenthal (2014) have argued that eco labels are less effective in influencing consumers' purchase behavior. However, it is found effective to develop an attitude towards green products through eco labels. Therefore, companies should work on consumers' personality traits and other factors that could lead to the formation of an attitude for environmentally friendly products consumption. Because environmentally conscious consumers are more cautious which is depicted in their purchase decisions (Grimmer \& Bingham, 2013). Chen and Chang (2012) noted that number of factors affect consumer decision making in purchase of green products, such as green perceived risk, green perceived value and green trust. Companies need to work on green perceived risk because consumers avoid purchasing products which they believe as risky. Minimizing green perceived risk and maximizing green trust about companies' product enhances consumers trust for the green products and they would start considering green products purchase.

According to Rettie et al. (2012), consumers have high level of skepticism for green products due to greenwashing. Consumers have firm belief that green products are less effective in terms of their functional benefits and are expensive which are deemed to be consumed by small segment of consumers. Advertisements help firms generating favorable consumer response (Haq \& Ghouri, 2017). Atkinson and Rosenthal (2014) argued about deceptive advertisement claims by companies regarding green products and observed that consumers have less proclivity for products which they feel lacking in credibility. Consumer's perceived credibility about the firms and their offering have colossal impact on their purchase decision (Aslam, Batool, \& Haq, 2016). It is, therefore, imperative for the companies to be trustworthy in the eyes of consumers to excel in green segment. Credibility of the organization claims, and manufacturing less damaging products have tremendous effect on consumers' attitude for the green products which ultimately leads to green consumption. Consequently, consumers' trust on green claim act as a driving force to behave environmental friendly. Hence, it can be hypothesized that:

$H_{3}$ : Consumers' understanding of eco labels positively influence Consumer's Eco Conscious Buying Behavior mediated by consumers' trust on green claim.

\section{Environmental Concern and Consumer Eco Conscious Behavior}

Wei et al. (2017) investigated green consumption and defined that it includes various aspects of sustainability, which ensure safety of the planet. Manufacturers of green products can make products after the identification of factors that influence consumer decision making process. Consumers have deep emotional engagement to the safety of environment that could help in pursuance of products which are less damaging to the environment. Sheth et al. (2011) argued that human actions have depleted many natural resources leading to the issues of fisheries, deforestation, soil erosion and biodiversity. Xie, Bagozzi, 
and Grønhaug (2015) explained that consumers who have high regard for the sustainability of environment will support green initiatives and condemn companies that are involved in environmental degradation. Leonidou et al. (2013) noted that companies use variety of tools to communicate with the consumers' regarding environmental claims. Green promotion strategies of the companies include environmentally friendly packaging, portraying environmental image through advertising and making efforts to publicize environmental claims. However, do Paço and Reis (2012) suggested that consumers who are more conscious about the safety of environment tend to be more skeptical in their actions. Hartmann and Apaolaza-Ibáñez (2012) postulated that consumers concern for environment has boosted their purchase intention. Polonsky (2011) noted that pro environmental belief have strong effect on consumer green behavior. Furthermore, strong relationship exists between health promotion and concern for the environment which is ultimately supporting green products purchase behavior (Testa et al., 2015).

Paswan, Guzmán, and Lewin (2017) suggested that future benefits of conservation may not result in pro environmental behavior; it can only activate pro environmental behavior which is not consistent with deeper environmental behavior. The positive and negative aspects of green products may include cultural incompatibility, risk and product, consumers' intention and behavior are dependent upon evaluation of benefits and safety associated with environmental friendly products (Sun, Teh, \& Linton, 2018; Hazen, Mollenkopf, \& Wang, 2017). It is expected that eco labels are an imperative source of information for consumers, this ultimately shape their thinking pattern towards environment, and consumers concern for the safety and environmental issues increases. Thus, it can be hypothesized that:

\section{$H_{4}$ : Consumers' understanding of Eco labels positively influence environmental concern.}

Eco-labelling provides information to consumers related to green products. Marketers use eco-labelling strategy to create value for green products to motivate decision makers to adopt sustainable production (Miranda-Ackerman \& Azzaro-Pantel, 2017). Companies are focusing to establish market and build an image through its green products. In view of environmental concern, consumers have developed high tendency towards ecofriendly products (Chen \& Chang, 2013). The movement of "going green" is gaining momentum as consumers are becoming more conscious about environment. Consumers are looking for the products that are less damaging for the environment. Consumers' consistent evaluation and demand for eco-friendly products have motivated companies in maintaining the sustainability of environment (Nagaraju \& Thejaswini, 2014). Companies have changed their marketing approaches in response to consumers' environmental friendly behaviors (Chen \& Chang, 2013). However, the performance of green products is depicting gloomy picture in terms of market share. There is a clear dichotomy regarding consumers purchase intention and concern for the environment. Despite achieving environmental certification, products failed to gain consumers acceptability. Environmental concern has been investigated in this study to find out the causes of consumers motivating forces in selection of environmentally friendly products. Some studies have focused on consumer demographic characteristics that can shape preferences for the green prod- 
ucts (Testa et al., 2015). Labels are vital source of information for consumers; consumers are consistently involved in search of information regarding the products, which they want to purchase (Hameed, Siddiqui, \& Husain, 2015). Labels provide relevant information regarding the production processes and attributes of the products, environmental impact and origin. Manufacturers need to strategically market the products in a way that should capture maximum segments of the target market (Bullock, Johnson, \& Southwell, 2017). Eco-labeling programs by companies will help to communicate environmental and safety benefits associated with the products and production process with the consumers. By doing so, manufacturer establish a link with industry, provide information to pro environmental engineers and scientists, and devise a mechanism that support truly green sustainable future (Long, 2018). It can be inferred that consumers who have developed tendency towards the protection of environment based on eco labels understanding will prefer products that are green and less detrimental to the environment. Hence, it can be hypothesized that:

$H_{5}$ : Consumers' understanding of eco labels positively influence eco-conscious consumer buying behavior mediated by environmental concern.

$H_{6}$ : Consumers' trust on green labelling will positively influence environmental concern.

Figure 1

Research Framework Adapted from Martínez (2015)

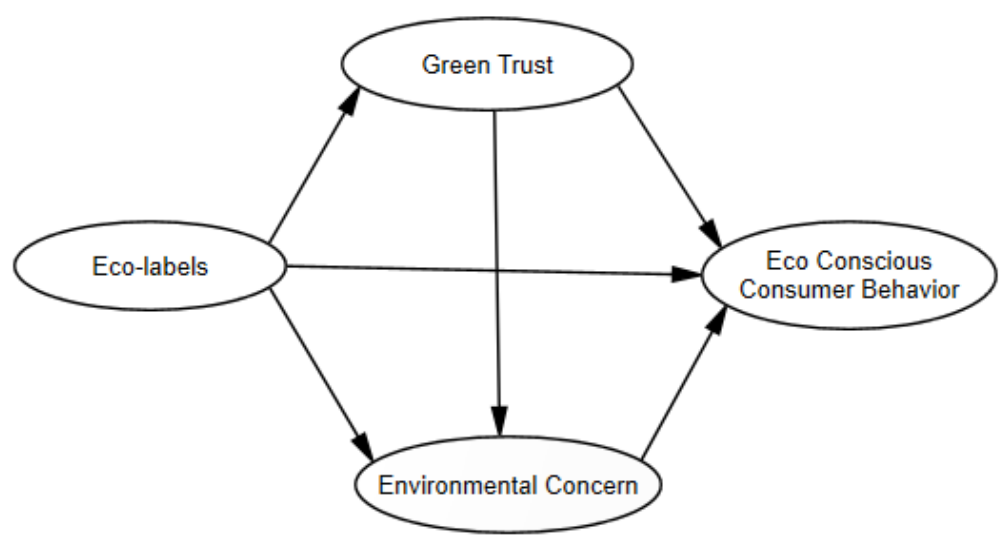

The conceptual The model in figure 1 focuses on the effectiveness of eco labels to elicit consumer response towards the sustainability of the environment. For instance, Martínez (2015) explored customer loyalty: the antecedents from green marketing perspective. Current conceptual model in figure 1 proposes that consumers' understanding of eco labels will positively affect consumers' eco conscious behavior. Additionally, it will analyze the effects of green trust and consumers' environmental concern direct and indirect effect on eco-conscious behavior. Based on prior research on the mediating role of green trust and 
environmental concern in other studies of Martínez (2015); and Reich and Soule (2016), these variables have been used as mediators in the conceptual model, as shown above in Figure 1.

\section{Research Methodology}

\section{Data Collection and Sampling}

This section deals with the collection of data and sampling procedure. Procedure of Data collection and sample size was determined based on previous literature regarding green consumers. Researchers noted that collection of responses from a big metropolitan city is better to predict overall population responses (Ritter, Borchardt, Vaccaro, Pereira, \& Almeida, 2015; Bailey et al., 2016). Karachi is the most populous city of Pakistan, and due to its cultural and ethnic diversity, it represents collective belief of overall consumers in Pakistan. Many authors have used convenience sampling for data collection as prior databases or records of consumers were not available to select randomly (Ritter et al., 2015; Mohd Suki, 2016; Dekhil, Boulebech, \& Bouslama, 2017). Moreover, it is easier for researchers to collect data through convenience sampling. On the premise of previous research and literature, convenience sampling was applied for the collection of respondents' data. Sample size of 300 respondents was gathered to analyze the effect of eco labels on consumers. 300 is the average sample for a large population and this sample size is based on previous researches in the field of green marketing (Bailey et al., 2016; Felix \& Braunsberger, 2016; Dekhil et al., 2017).

\begin{tabular}{lcc}
$\begin{array}{l}\text { Table } 1 \\
\text { Sample Characteristics }\end{array}$ & & \\
\hline Feature & N & Percentage (\%) \\
\hline Gender & & \\
\hline Male & 226 & 75.33 \\
Female & 74 & 24.66 \\
\hline Education & & \\
\hline Intermediate/ A level & 339 & 13.02 \\
Undergraduate & 371 & 23.66 \\
Graduate & 179 & 59.66 \\
Doctorate & 11 & 3.66 \\
\hline Occupation & & \\
\hline Employee & 121 & 40.33 \\
Own Business & 14 & 4.66 \\
Student & 165 & 55 \\
\hline
\end{tabular}

\section{Profile of Participants}

Table 1 is showing the profile of the respondents. Out of total, 75.33\% were male respondents and $24.66 \%$ were female respondents. $59.66 \%$ of the participants were at graduate level of study, followed by $23.66 \%$ undergraduate students, $13.02 \%$ of the respondents were intermediate and $3.66 \%$ were doctorate students. As far as occupation is concerned, 
$40.33 \%$ were employees, $55 \%$ were full time students, and $4.66 \%$ were operating their own businesses. In Pakistan, educated respondents have more knowledge about organic food's recycling detrimental effects on global warming than uneducated. Therefore, data has been collected from educated respondents. Federal government of Pakistan, provincial governments and social activists initiated green plantation campaigns to reduce the adverse effects of global warming. Karachi is called mini Pakistan, having representation from all provinces of Pakistan. Therefore, data has been gathered from Karachi city.

\section{Research Instrument and Measures}

Self-administered questionnaires have been distributed for the collection of consumers' responses regarding understanding the effectiveness of eco labels, environmental concern, consumer trust and Eco conscious consumer buying behavior. Questionnaires were divided into two sections: demographic profile of consumers and questions related to the hypothesized variables. All the items in the study were measured on a five-point Likert scale, where (5) represents "strongly agree" and (1) represents "strongly disagree". Second part of the questionnaire was comprised of questions related to consumers' evaluation of eco labels and its effects on eco-conscious consumer behavior. Eco labels were measured through three five-point Likert scale items from the study of Thøgersen et al. (2010). Consumers' concern for the environment was measured through three five-point Likert scale items from Paul, Modi, and Patel (2016); Ritter et al. (2015); scales were taken for the evaluation of consumers trust for eco labels. Leary, Minton, and Mittelstaedt (2016) five items scale have been used to assess eco conscious consumer behavior. Pilot study with 50 MBA students was conducted to understand their eco-conscious behavior. The values of cronbach's alpha for the items were below the threshold value 0.70 . According to J. F. Hair, Black, Babin, Anderson, and Tatham (2009), the values in the range of 0.70 to 0.90 are acceptable. Though aware of these borderline values, instruments were adapted based upon previous studies. However, few modifications have been made in the instruments by removing the elements having low cronbach's alpha values, as proposed by J. F. Hair et al. (2009).

\section{Data Analysis and Results}

Table 2

Discriminant validity analysis, Means, and correlations of constructs.

\begin{tabular}{|c|c|c|c|c|c|c|}
\hline Constructs & Means & S.D & $\begin{array}{c}\text { Eco Conscious Buying } \\
\text { Behavior }\end{array}$ & $\begin{array}{c}\text { Green } \\
\text { Trust }\end{array}$ & $\begin{array}{c}\text { Environmental } \\
\text { Concern }\end{array}$ & Eco Label \\
\hline Eco conscious buying behavior & 3.5422 & 0.624 & 0.676 & & & \\
\hline Green Trust & 3.7422 & 0.609 & $0.361^{* *}$ & 0.550 & & \\
\hline Environmental Concern & 3.9422 & 0.669 & $0.160^{* *}$ & $0.393^{* *}$ & 0.664 & \\
\hline Eco Label & 3.7200 & 0.732 & $0.331^{* *}$ & $0.267^{*}$ & $0.328^{* *}$ & 0.707 \\
\hline
\end{tabular}




\section{Confirmatory Factor Analysis}

Cronbach's alpha was used to assess the reliability of the measurement items. Though final results showing low CFA values, we accepted the results based on previous research findings on same instruments. Main reason to include low CFA values is the study conducted in developing market context. Data was collected from Pakistani consumer, they have less propensity towards green products due to insufficient campaign by government and companies. Factor loading of items would have been higher if consumers had more knowledge regarding the benefits of using green products. According to J. Hair, Anderson, Tatham, and Black (1998), the level of internal consistency for the four constructs should exceed the minimum requirement of 0.60 for an exploratory study. The internal consistency of four constructs were ranging from 0.633 to 0.691 which exceeds the minimum threshold of 0.60 . To assess convergent validity, standardized factor loadings for all measurement items and average variance extracted were estimated. All measurement items had standardized loading estimates of .5 or higher and all were significant at alpha level of .001. The items below 0.50 loading were deleted from the analysis as recommended by Paul et al. (2016). Overall Cronbach's alpha for 20 items was 0.824 which is more than threshold value of 0.70. According to Fornell and Larcker (1981), the value of average variance extracted (AVE) must be greater than the correlation among the constructs as shown in table 3 (confirming discriminant validity). For instance, the AVE's for the two constructs: eco-conscious consumer behavior and green trust are 0.676 and 0.55 which are greater than the correlation value of 0.361 . Hence, it shows that there is adequate discriminant validity between the constructs. Values of all AVEs are confirming discriminant validity in the model.

\section{Structural Model Results}

Result of the SEM indicates overall model a fit (J. F. Hair et al., 2009): $\chi^{2}=83.131$; df $=48 ; \mathrm{p}=0.001$. Byrne (1994) suggested the value for GFI and CFI should be .90 and .93 respectively. MacCallum, Browne, and Sugawara (1996) suggested that the value of RMSEA should be 0.01 for excellent model fit, 0.05 for good and 0.08 for mediocre fit. The values of model fit are falling in the ranges proposed by authors such as: AGFI=.929; $\mathrm{GFI}=.957 ; \mathrm{NFI}=.873 ; \mathrm{CFI}=.941 ; \mathrm{RMSEA}=0.049$ shown in table 3 .

The findings of structural equation model show that Eco labels have positive influence on eco-conscious consumer behavior $(\beta=.45)$, Eco labels have positive influence on green trust $(\beta=.40)$, Eco labels have positive influence on environmental concern $(\beta=.32)$. Positive influence of eco labels on eco-conscious consumer behavior mediated by green trust is accepted with the path coefficient $(\beta=.56)$. While path coefficient of environmental concern as a mediator between eco labels and eco-conscious consumer behavior is rejected with the negative path coefficient of $\beta=-.32$. Positive influence of green trust on environmental concern is accepted with the standard coefficient value of $\beta=.50$. From the above analysis it is concluded that all hypotheses were accepted except mediating influence of environmental concern between eco labels and eco-conscious consumer behavior. 
Table 3

\begin{tabular}{lccc}
\hline Hypothesis & Proposed effects & Path Coefficients & Results \\
\hline H1 & + & 0.45 & H1 is supported \\
H2 & + & 0.4 & H2 is supported \\
H3 & + & 0.32 & H3 is Supported \\
H4 & + (mediation) & 0.56 & H4 is supported \\
H5 & + (mediation) & -0.32 & H5 is not Supported \\
H6 & + & 0.5 & H6 is supported \\
NFI $=.873$ & CFI $=.941$ AGFI $=.929$ & GFI $=.957$ & RMSEA $=0.049$ \\
\hline
\end{tabular}

Table 4

Sobel test Mediation Analysis

\begin{tabular}{lcc}
\hline & Estimates & S.E \\
\hline $\mathrm{EL} \rightarrow \mathrm{GT}$ & 0.28 & 0.077 \\
$\mathrm{GT} \rightarrow$ ECCB & 0.959 & 0.285 \\
$\mathrm{EL} \rightarrow \mathrm{EC}$ & 0.408 & 0.132 \\
$\mathrm{EC} \rightarrow$ ECCB & -0.296 & 0.153 \\
\hline
\end{tabular}

Z-value of green trust is 2.47 after applying sobel test analysis. This value is greater than 1.96, which signifies that green trust is a mediator in the model. While Z-Value for Environmental Concern is -1.64, it's falling in the critical region of 1.96 depicts that environmental concern is not a mediator in the proposed model. For the analysis of full, partial and no mediation, we ran 1000 bootstrapping samples in AMOS. Full mediation occurs when indirect is less than 0.05 and direct is greater than 0.05 which can be found in case of green trust (GT). Indirect effect value greater than 0.05 signifies no mediation, the value of environmental concern is .258 which is greater than 0.05 , verifies no mediation shown in table 5 .

Table 5

Analysis of Mediation effects

\begin{tabular}{lccc}
\hline & Direct effect & Indirect effect & Total effect \\
\hline Green Trust & 0.280 & 0.000 & 0.280 \\
Environmental concern & 0.408 & 0.258 & 0.665 \\
\hline
\end{tabular}

Table 5 is showing the Sobel test mediation effects. Eco label is the independent variable, environmental concern and green trust are mediating variables. First of all, the values in indirect effects column were checked, value of mediating variable is greater than 0.05 , which shows no mediation in the analysis. The value of green trust is 0.000 which is less than 0.05 proved that green trust is a mediating variable and environmental concern value is greater than 0.05 , which signifies no mediation. For the confirmation of partial and full mediation, we must check the values of direct and indirect columns. Full mediation occurs when indirect is less than 0.05 and direct is greater than 0.05 . Green trust is acting as a full mediator in the proposed model as it is fulfilling the full mediation criteria.

\section{Discussion}

The purpose of this research was to examine the effects of eco labels on consumer eco conscious behavior, the effects of two mediating variables were considered: environmen- 
tal concern and green trust. Eco label is an imperative source of information about environmentally friendly products; eco conscious consumer tends to invest more time in probing about hazardous effects of products on health and environment. Polonsky et al. (2012) argued that consumer knowledge precedes pro environmental attitude and behavior. Hence, the study findings support the arguments suggested by previous researches in the area of green marketing. The current research fills the gap by investigating the effects of eco labels on pro environmental behavior of consumers. Eco labels are the primary source of information for the consumers. Additionally, the mediating effects of environmental concern and consumers' trust towards eco conscious consumer behavior have credible contribution in the area of green marketing, that provides substantial guidelines to practitioners and consumers towards the sustainability of environment. Detail discussions for the variables in study are as follow:

\section{Eco Labels and Eco Conscious Consumer Behavior}

Eco labels has emerged out as one of the most indispensable variable in the literature of green marketing that adds value to the attributes of product. Developed countries have used eco labels, and they found eco labels an effective source of information, adding values in the features of green products. This paper includes the data of consumers from a developing country, i.e., Pakistan. Understanding consumers' acceptability of eco labels in developing country is an essential aspect of this paper, to predict future need of consumers and their propensity to consume eco- labelled products. This research will fill the inconsistency that exists in the literature of green marketing related to green products' labelling in developing markets. In this context, prominent stakeholders such as regulators, government policies makers and corporate sectors play a vital role in defining and shaping consumers' opinion for the green products through eco labelling. Our findings revealed that consumers are adaptive towards eco-labels and get influenced by the benefits associated with the products that lead to green products consumption. Manufacturers need to design eco-labeled products that capture consumer's desire towards green products. Successful designing of eco-labels will ultimately induce consumer to behave pro-environmentally.

\section{Eco Labels and Green Trust}

Across the world, there are certain criterion established for the claim of green products. Such claims are validated by an independent authority that provides certification for green products. Subsequently companies use approved certifications for the promotion of products through eco labels. It has been observed that consumers who have the knowledge of green products and probe for it are afraid of greenwashing. Consumers' trust on eco labels that have significant impact on pro environmental behavior which is consistent with the findings of Atkinson and Rosenthal (2014) and Testa et al. (2015). Eco labels, sometimes, have cogent source of certification which compel consumers to accept the green claims. Moreover, consumers believed that companies using eco labels are maintaining highest standards to support and preserve the environment. Foremost man- 
agerial implication of this research is the consumer trust about green claims made by the companies. To develop eco conscious consumer behavior, managers need to ingrain the trust about the green claims. It has been found that green trust has significant impact on consumer decision making regarding green products acceptability. Thus, consumers who hold positive attitude towards company's green claims would be willing to accelerate their consumption of green products.

\section{Eco Labels, Environmental Concern and Consumer Behavior}

Environmental concern has become an integral part of companies' policies and governments around the world. Preserving environment form hazardous consumption and conforming the standard regulations to maintain highest standard would project companies' responsible attitude towards the environment. Manufacturers design eco-labels to portray the significance of environment, and at the same time promote effective attributes of the products to consumers. Findings suggest that, consumers have regard for the sustainability of environment and they want to preserve it, but they are more inclined towards the functional benefits. However, environmental benefits through eco labels are less appealing to consumers' emotions. Therefore, it is imperative for the manufacturer to be more vigilant in the design of eco labels that help consumer to accept the attributes of green products, a value addition to product. Moreover, management need to work on the understanding of consumer psyche regarding environmental products acquisition and potential effects of consumer behavior towards the safety of environment. The findings related to consumer's environmental concern are inconsistent with the previous researches (Hartmann \& Apaolaza-Ibáñez, 2012; Polonsky, Vocino, Grimmer, \& Miles, 2014). Thus, robust policies are needed to be implemented to raise substantial awareness about the sustainability of environment. Producers and government regulators need to emphasize the importance of environment through media campaigns in developing countries, which will help them to increase consumer knowledge regarding the susceptibility of environment, which is associated with hazardous productions.

\section{Green Trust and Environmental Concern}

Another issue considered in the model was the impact of green trust on consumers' proclivity towards sustainability of environment. Green trust has meaningful impact on consumer's tendency for the safety of environment. Information acquired from the eco labels served to deliver the intended message which arise consumers concern to preserve the environment. Consumers probe more related to products' attribute, production processes and impact of company's policies on the environment. Such concerns contributed to consumer inclination for the safety of environment thus led to pro-environmental behavior. 


\section{Conclusion}

Current research intends to explain the relationship between eco-labels and eco-conscious consumer behavior. Many studies, in the past, have emphasized the different aspect of green products and consumer behavior. However, this study has filled the gap by analyzing effectiveness of eco-labels which are the prime and immediate source of information to consumers at the point of purchase. Eco-labels are certified labels used by manufacturers to provide relevant information regarding product's environmental friendly attributes. This study has also incorporated two other novel variables as mediators between the relationship of eco-labels and eco-conscious behavior. Addition of two mediators - "green trust" and "environmental concern" are pertinent in this study as these two factors can contribute a lot in research framework. Green trust has been proved a vital factor in the literature of green marketing because consumers around the world are very much concerned about greenwashing. Many companies made claims about the greenery of product, but it is opposite. Therefore, green trust has significant role in defining consumers' acceptability of green products. Besides this, environmental concern has been used as mediator. Environmental concern is the burning issue across the globe; there are many summits regarding the sustainability of environment which compelled govt, manufactures to comply the standard rules for the safety of environment. Outcomes of these summits and conferences, has largely, blamed the organizations for their hazardous production processes that led to the degradation of environment. The findings of this study depict that consumers get influenced by eco-labels which help them to be environmentally conscious. The effect of green trust on eco-conscious consumer behavior has been proved, which signifies that green trust has positive influence on consumer ecoconscious behavior. Moreover, the effect of eco-labels on green trust was also significant and positive; which implies that eco-labels are the true source of information for the green products. The study further focused the effects of eco-labels on environmental concern. It was found that eco-labels effects environmental concern positively. It was found that eco-labels effect consumer concern for the safety of environment; it also confirmed the suitability of eco-labels to carry environmental friendly messages.

However, the impact of environmental concern on consumer's eco-conscious behavior was not found. This is particularly related to consumers actual behavior. The reason for consumers' reluctance towards eco-conscious behavior could be the lifestyle of consumers, which is not actually relevant to green market. Second reason could be the country in which this research has been conducted as green laws are not practically implemented in letter and spirit. Third, consumers' might have environmental concern, but they couldn't get opportunity to transform their environmental attitude towards environmental behavior due to lack of green products. Thus, these reasons act as a bottleneck in the way of actual behavior of consumers. This research has also emphasized the relationship between green trust and environmental concern. The findings show that green trust has positive influence on environmental concern. This suggest that consumer trust for green products make them conscious about the safety of environment.

The results of the study depict a significant direct impact of eco labels on consumer's eco conscious behavior, green trust and environmental concern. In addition to this, study 
shows positive effects of eco labels on eco conscious consumer behavior fully mediated by green trust i.e., green trust positively influences environmental concern. This study fails to provide empirical evidence that environmental concern mediates the relationship between eco labels and eco conscious consumer behavior. The findings of this study provide a new framework and contribute into existing literature of green marketing research.

\section{Limitations and Future Research}

Firstly, the data of respondents have been collected from one metropolitan city of Pakistan, which could make the results biased. Data from other cities would portray better scenario as behavioral pattern of consumers are different in different cities and new results might improve values of confirmatory factor analysis. The study is not specific to any product category and lacks physical appearance of eco labels that could have meaningful impact in understanding eco conscious consumers behavior. Moreover, cross sectional data have been used to understand consumer's eco conscious behavior, future research can be done by using longitudinal data to find the differences in consumers' behavior for the better understanding of eco labels. The impact of education and environmental knowledge were not considered in the model, addition of these two constructs as moderators will shed more light in understanding consumer environmental behavior as understanding of eco-labels in 21st century would be having substantial impact on consumer eco conscious behavior. This research is based on anticipated eco-labels, research can be conducted on actual eco-labels of certain products which may have more predictive power eliciting consumers' actual behavior, which will help researchers to substantiate current research findings. Like most of the survey researches, convenience sampling approach has been used in main locations such as hyper stores, universities, super stores and malls. To substantiate this research findings, future research can be conducted in different geographical locations. Although current model has enough predictability for consumer eco-conscious behavior, but its predictability can be further improved by adding factors that are crucial for pro environmental behavior. 


\section{References}

Aslam, W., Batool, M., \& Haq, Z. U. (2016). Attitudes and behaviour of the mobile phones users towards SMS advertising: A study in an emerging economy. Journal of Management Sciences, 3(1), 63-80.

Atkinson, L., \& Rosenthal, S. (2014). Signaling the green sell: The influence of eco-label source, argument specificity, and product involvement on consumer trust. Journal of Advertising, 43(1), 33-45.

Bailey, A. A., Mishra, A., \& Tiamiyu, M. F. (2016). Green consumption values and Indian consumers' response to marketing communications. Journal of Consumer Marketing, 33(7), 562-573.

Bullock, G., Johnson, C., \& Southwell, B. (2017). Activating values to stimulate organic food purchases: Can advertisements increase pro-environmental intentions? Journal of Consumer Marketing, 34(5), 427-441.

Chan, E. S.-w. (2014). Green marketing: Hotel customers' perspective. Journal of Travel $\mathcal{E}$ Tourism Marketing, 31(8), 915-936.

Chekima, B., Wafa, S. A. W. S. K., Igau, O. A., Chekima, S., \& Sondoh Jr, S. L. (2016). Examining green consumerism motivational drivers: Does premium price and demographics matter to green purchasing? Journal of Cleaner Production, 112(4), 34363450 .

Chen, Y.-S., \& Chang, C.-H. (2012). Enhance green purchase intentions: The roles of green perceived value, green perceived risk, and green trust. Management Decision, 50(3), 502-520.

Chen, Y.-S., \& Chang, C.-H. (2013). Greenwash and green trust: The mediation effects of green consumer confusion and green perceived risk. Journal of Business Ethics, 114(3), 489-500.

Cronin, J. J., Smith, J. S., Gleim, M. R., Ramirez, E., \& Martinez, J. D. (2011). Green marketing strategies: An examination of stakeholders and the opportunities they present. Journal of the Academy of Marketing Science, 39(1), 158-174.

Davies, J., Foxall, G. R., \& Pallister, J. (2002). Beyond the intention-behaviour mythology: An integrated model of recycling. Marketing Theory, 2(1), 29-113.

Dekhil, F., Boulebech, H., \& Bouslama, N. (2017). Effect of religiosity on luxury consumer behavior: The case of the Tunisian muslim. Journal of Islamic Marketing, 8(1), 74-94.

Delmas, M. A., \& Lessem, N. (2017). Eco-premium or eco-penalty? Eco-labels and quality in the organic wine market. Business $\mathcal{E}$ Society, 56(2), 318-356.

do Paço, A. M. F., \& Reis, R. (2012). Factors affecting skepticism toward green advertising. Journal of Advertising, 41(4), 147-155.

D'Souza, C., Taghian, M., Sullivan-Mort, G., \& Gilmore, A. (2015). An evaluation of the role of green marketing and a firm's internal practices for environmental sustainability. Journal of Strategic Marketing, 23(7), 600-615.

Felix, R., \& Braunsberger, K. (2016). I believe therefore I care: The relationship between religiosity, environmental attitudes, and green product purchase in Mexico. International Marketing Review, 33(1), 137-155. 
Fishbein, M., \& Ajzen, I. (1977). Belief, attitude, intention, and behavior: An introduction to theory and research. Philosophy and Rhetoric, 10(2), 130-132.

Fishbein, M., \& Ajzen, I. (1980). Understanding attitudes and predicting social behavior. Englewood Cliffs, NJ: Prentice-Hall.

Fornell, C., \& Larcker, D. F. (1981). Structural equation models with unobservable variables and measurement error: Algebra and statistics. Journal of Marketing Research, 18(1), 382-388.

Gordon, R., Carrigan, M., \& Hastings, G. (2011). A framework for sustainable marketing. Marketing Theory, 11(2), 143-163.

Gotschi, E., Vogel, S., Lindenthal, T., \& Larcher, M. (2009). The role of knowledge, social norms, and attitudes toward organic products and shopping behavior: Survey results from high school students in Vienna. The Journal of Environmental Education, 41(2), 88-100.

Green, T., \& Peloza, J. (2014). Finding the right shade of green: The effect of advertising appeal type on environmentally friendly consumption. Journal of Advertising, 43(2), 128-141.

Grimmer, M., \& Bingham, T. (2013). Company environmental performance and consumer purchase intentions. Journal of Business Research, 66(10), 1945-1953.

Hair, J., Anderson, R., Tatham, R., \& Black, W. (1998). Multivariate data analysis. Prentice Hall, Upper Saddle River, NJ.

Hair, J. F., Black, W. C., Babin, B. J., Anderson, R. E., \& Tatham, R. L. (2009). Multivariate data analysis. Prentice Hall, Upper Saddle River, USA.

Hameed, I., Siddiqui, S. J., \& Husain, J. (2016). Conceptualizing humor in advertising: The moderating role of self-monitoring. Pakistan Business Review, 18(3), 692-709.

Hameed, I., Siddiqui, S. J., \& Husain, J. 1. (2015). Disparagement as a processing stimulus for humor in advertising. IBT Journal of Business Studies, 11(1), 82-101.

Haq, M. A., \& Ghouri, A. M. (2017). Distinctive characteristics of mobile advertising in measuring consumers' attitude: An empirical study. Journal of Management Sciences, $4(2), 199-216$.

Hartmann, P., \& Apaolaza-Ibáñez, V. (2012). Consumer attitude and purchase intention toward green energy brands: The roles of psychological benefits and environmental concern. Journal of Business Research, 65(9), 1254-1263.

Hasnah Hassan, S. (2014). The role of islamic values on green purchase intention. Journal of Islamic Marketing, 5(3), 379-395.

Haws, K. L., Winterich, K. P., \& Naylor, R. W. (2014). Seeing the world through green-tinted glasses: Green consumption values and responses to environmentally friendly products. Journal of Consumer Psychology, 24(3), 336-354.

Hazen, B. T., Mollenkopf, D. A., \& Wang, Y. (2017). Remanufacturing for the circular economy: An examination of consumer switching behavior. Business Strategy and the Environment, 26(4), 451-464.

Hornibrook, S., May, C., \& Fearne, A. (2015). Sustainable development and the consumer: Exploring the role of carbon labelling in retail supply chains. Business Strategy and the Environment, 24(4), 266-276.

Leary, R. B., Minton, E. A., \& Mittelstaedt, J. D. (2016). Thou shall not? The influence of 
religion on beliefs of stewardship and dominion, sustainable behaviors, and marketing systems. Journal of Macromarketing, 36(4), 457-470.

Lee, J., Bhatt, S., \& Suri, R. (2018). When consumers penalize not so green products. Psychology \& Marketing, 35(1), 36-46.

Leonidou, C. N., Katsikeas, C. S., \& Morgan, N. A. (2013). “Greening” the marketing mix: Do firms do it and does it pay off? Journal of the Academy of Marketing Science, 41(2), 151-170.

Long, D. C. (2018). Greening of consumer cleaning products. Green Techniques for Organic Synthesis and Medicinal Chemistry, 91-115. doi: 10.1002/9781119288152.ch5

MacCallum, R. C., Browne, M. W., \& Sugawara, H. M. (1996). Power analysis and determination of sample size for covariance structure modeling. Psychological Methods, $1(2), 130$.

Martínez, P. (2015). Customer loyalty: Exploring its antecedents from a green marketing perspective. International Journal of Contemporary Hospitality Management, 27(5), 896917.

Miranda-Ackerman, M. A., \& Azzaro-Pantel, C. (2017). Extending the scope of ecolabelling in the food industry to drive change beyond sustainable agriculture practices. Journal of Environmental Management, 204, 814-824.

Mohd Suki, N. (2016). Green product purchase intention: Impact of green brands, attitude, and knowledge. British Food Journal, 118(12), 2893-2910.

Mustonen, N., Karjaluoto, H., \& Jayawardhena, C. (2016). Customer environmental values and their contribution to loyalty in industrial markets. Business Strategy and the Environment, 25(7), 512-528.

Nagaraju, D., \& Thejaswini, H. (2014). Consumers' perception analysis-market awareness towards ecofriendly FMCGS products-a case study of mysore district. IOSR Journal of Business and Management, 16(4), 64-71.

Paswan, A., Guzmán, F., \& Lewin, J. (2017). Attitudinal determinants of environmentally sustainable behavior. Journal of Consumer Marketing, 34(5), 414-426.

Paul, J., Modi, A., \& Patel, J. (2016). Predicting green product consumption using theory of planned behavior and reasoned action. Journal of Retailing and Consumer Services, 29, 123-134.

Polonsky, M. J. (2011). Transformative green marketing: Impediments and opportunities. Journal of Business Research, 64(12), 1311-1319.

Polonsky, M. J., Vocino, A., Grau, S. L., Garma, R., \& Ferdous, A. S. (2012). The impact of general and carbon-related environmental knowledge on attitudes and behaviour of US consumers. Journal of Marketing Management, 28(3-4), 238-263.

Polonsky, M. J., Vocino, A., Grimmer, M., \& Miles, M. P. (2014). The interrelationship between temporal and environmental orientation and pro-environmental consumer behaviour. International Journal of Consumer Studies, 38(6), 612-619.

Reich, B. J., \& Soule, C. A. A. (2016). Green demarketing in advertisements: Comparing "buy green" and "buy less" appeals in product and institutional advertising contexts. Journal of Advertising, 45(4), 441-458.

Rettie, R., Burchell, K., \& Riley, D. (2012). Normalising green behaviours: A new approach to sustainability marketing. Journal of Marketing Management, 28(3-4), 420-444. 
Ritter, A. M., Borchardt, M., Vaccaro, G. L., Pereira, G. M., \& Almeida, F. (2015). Motivations for promoting the consumption of green products in an emerging country: Exploring attitudes of Brazilian consumers. Journal of Cleaner Production, 106, 507520.

Sheth, J. N., Sethia, N. K., \& Srinivas, S. (2011). Mindful consumption: A customer-centric approach to sustainability. Journal of the Academy of Marketing Science, 39(1), 21-39.

Sun, H., Teh, P.-L., \& Linton, J. D. (2018). Impact of environmental knowledge and product quality on student attitude toward products with recycled/remanufactured content: Implications for environmental education and green manufacturing. Business Strategy and the Environment, 27(7), 935-945.

Testa, F., Iraldo, F., Vaccari, A., \& Ferrari, E. (2015). Why eco-labels can be effective marketing tools: Evidence from a study on Italian consumers. Business Strategy and the Environment, 24(4), 252-265.

Thøgersen, J., Haugaard, P., \& Olesen, A. (2010). Consumer responses to ecolabels. European Journal of Marketing, 44(11/12), 1787-1810.

Wei, C.-F., Chiang, C.-T., Kou, T.-C., \& Lee, B. C. (2017). Toward sustainable livelihoods: Investigating the drivers of purchase behavior for green products. Business Strategy and the Environment, 26(5), 626-639.

Xie, C., Bagozzi, R. P., \& Grønhaug, K. (2015). The role of moral emotions and individual differences in consumer responses to corporate green and non-green actions. Journal of the Academy of Marketing Science, 43(3), 333-356.

Yeniaras, V. (2016). Unpacking the relationship between materialism, status consumption and attitude to debt: The role of islamic religiosity. Journal of Islamic Marketing, 7(2), 232-247.

Zinkhan, G. M., \& Carlson, L. (1995). Green advertising and the reluctant consumer. Journal of Advertising, 24(2), 1-6. 